\title{
GESTIÓN DE LA COMUNICACIÓN EN LA SOCIEDAD DEL SIGLO XXI: UN "ARMA" SUTIL PARA UNA GLOBALIZACIÓN BAJO SOSPECHA
}

\section{COMMUNICATION MANAGEMENT IN THE 21ST CENTURY SOCIETY: "A SUBTILE TOOL UNDER SUSPICION"}

\author{
AUTOR \\ Javier Díez Medrano \\ Universidad Europea de Madrid/Universidad Complutense de Madrid (España) \\ javierdiez1962@yahoo.es
}

\section{RESUMEN}

La gestión de la comunicación tiene un complicado cometido social en el inicio del siglo XXI, en la medida en que puede devolver la dignidad al concepto de "globalización", un concepto adulterado por quienes lo han utilizado indebidamente para defender actuaciones políticas, económicas y sociales cuyos fines están frecuentemente orientados, paradójicamente, en dirección opuesta al sentido ideal y positivo de dicho concepto. La siguiente reflexión expone cómo los agentes próximos al núcleo del poder ejercen ese control sobre la comunicación y la información desde las culturas y sociedades post materialistas, en contradicción con las expectativas de las sociedades pre industriales.

\section{PALABRAS CLAVE}

Globalización - Comunicación - Información - Gestión - Ecosistema 


\section{ABSTRACT}

Communication Management involves a hard to understand social commitment at the beginning of the XXI Century as it may bring back dignity to the "Globalization" concept, a concept wrongly used for some actors whose intentions were oriented to gain political, economical or social influence and power over society, in an opposite direction to the original that was pretended by the purest globalization movement. The current reflexion expresses how the different closest actors to Power play in order to control communication and information. They are actors living in post materialist societies and running in a contradictory way for the pre industrial societies expectances and hopes.

\section{KEY WORDS}

Globalization - Communication - Information - Management - Ecosystem

\section{ÍNDICE}

1. Gestión de la Comunicación en la Sociedad del Siglo XXI: Un "Arma" sutil para una Globalización Bajo Sospecha

2. Filosofía de la Globalización

3. Bibliografía 


\section{Gestión de la Comunicación en la Sociedad del Siglo XXI: Un "Arma" Sutil para una Globalización Bajo Sospecha}

La gestión correcta de la comunicación tiene un complicado cometido social en el inicio del actual siglo XXI, en la medida en que puede devolver la dignidad al exprimido y mal comunicado concepto de "globalización", un concepto adulterado por quienes to han utilizado indebidamente para defender actuaciones políticas, económicas y sociales cuyos fines están frecuentemente orientados, paradójicamente, en dirección opuesta al sentido ideal y positivo de dicho concepto.

La "globalización" tiende a generar un rechazo creciente tanto en las sociedades más avanzadas como en las menos desarrolladas de nuestro planeta y ello obedece a que los agentes próximos al núcleo del poder, es decir quienes controlan la comunicación y la información en las culturas integradas en "el primer mundo", han edificado su desarrollo menospreciando la consistencia de los cuatro pilares del llamado "ecosistema social", a saber, la población, el medioambiente, la tecnología y las organizaciones sociales.

Son numerosos los autores que han definido la globalización como un proceso social, cultural, económico y tecnológico. No deja de ser irónico si se considera que el fenómeno de la globalización emana de un proceso político, y en particular de una coyuntura geoestratégica militar, el fin de la "Guerra Fría". En todo caso, los efectos sobre la información y la comunicación son eso, efectos, en ningún caso causas explicativas del fenómeno analizado en este caso.

El concepto de "globalización" va frecuentemente asociado a términos como interdependencia, democratización, unificación y multiculturalismo, en la medida en 
que la revolución tecnológica canalizada a través de Internet hace posible dinamizar los intercambios de información $y$, por lo tanto, el conocimiento sobre los comportamientos, las actitudes, los hábitos, las creencias y los valores de otras sociedades y culturas diferentes a la nuestra, sin olvidar la cara documental sobre la especificidad económica, financiera y política del mundo exterior.

Sin embargo, existe un aspecto que contamina este modo de entender la globalización: La integración de las economías locales en una economía de mercado mundial en la que la riqueza y la producción real es relegada a un segundo plano de importancia para ceder su paso a los movimientos libres de capital y universalizar la sociedad de consumo al margen de la economía real de las sociedades.

En otras palabras, la globalización ha dado lugar a un mercado planetario de valores, o lo que es lo mismo, a la hegemonía de un poder financiero anónimo, sin estructura conocida, sin identidad nacional, internacional, multinacional ni supranacional, un poder ajeno al control de las estructuras convencionales que la historia construyó para regular éticamente los poderes legislativo, ejecutivo y judicial. La globalización que estamos viviendo escapa al control de los Estados que la impulsaron en la segunda mitad del siglo XX (principalmente los gobiernos americano, soviético y japonés, que optaron por limitar las misiones militares de sus satélites para potenciar su función en favor de utilidades de telecomunicaciones) y se convierte en un proceso controlado por un "poder" muy superior al de los gobiernos y las multinacionales. Algunos han apuntado a ciertos lobbies como los nuevos amos de la globalización, pero no todos los expertos se ponen de acuerdo sobre la identidad de dichos grupos de poder ni tampoco es el objeto de este análisis.

Durante la primera fase del siglo XXI, la gestión de la comunicación no puede ignorar la evolución que está tomando este proceso malinterpretado de "globalización", un concepto deliberadamente sesgado y que explicaría el creciente movimiento de rechazo mundial a esta supuesta filosofía de la vida sustentada supuestamente en la igualdad y la prosperidad de todas las organizaciones sociales del mundo, con 
independencia de las peculiaridades históricas, políticas, socio- económicas y culturales de los pueblos del mundo.

Es conocido que el ecosistema social depende en dos cuartas partes de la cultura, tanto por su representación material, o sea la tecnología, como por la inmaterial, es decir su sistema de valores. Los otros dos componentes interdependientes del ecosistema son la población mundial y el medioambiente donde se desenvuelve su vida.

El principal error de la comunicación generada por los países del primer mundo deriva de haber interpretado o trasladado a la opinión pública la idea de que la ruptura de las barreras del tiempo y del espacio en la comunicación generaba por sí sola un contexto de globalización, de modo que se daba por válido su desarrollo por el mero desarrollo de uno de los cuatro pilares del ecosistema, la tecnología, o lo que es lo mismo, la faceta material de la cultura, personalizada muchas veces en la ya consabida herramienta "world wide web".

Una vez universalizada la herramienta que permitía trasladar la información e intercambiar la cultura entre todos los seres humanos, se obviaba que sus efectos desencadenarían el resto de las virtudes asociadas a dicha globalización, es decir la igualdad y la prosperidad de los pueblos sin fronteras. Craso error. Esta concepción dela globalización ignoraba la segunda faceta de la cultura, la no material, la que alude a los sistemas de valores que enriquecen y conforman la diversidad de organizaciones sociales en el mundo.

Una gestión de la comunicación orientada a la aceptación de la globalización debe adoptar como propia la aspiración de preservar el ecosistema social mundial. Del mismo modo que la tecnología por sí sola no es suficiente para alcanzar esta meta, tampoco lo es la creencia de que el cuidado del medioambiente "per se" pone fin a las desigualdades sociales. 
Para que la población mundial tenga un mejor y más racional acceso a los recursos y disfrute de una rápida adaptación a su entorno, es innegable la necesidad de desarrollar la tecnología, si bien ello debe ir acompañado de una correcta comprensión y de un apoyo a las organizaciones sociales y las estructuras organizativas de cada sociedad, respetando sus sistemas de valores particulares y favoreciendo el crecimiento económico y el desarrollo cultural de las mismas, sin alterar por ello la esencia de su particularidad cultural, incluyendo sus creencias religiosas o los hábitos y costumbres autóctonas. Si la comunicación traslada esta forma de actuar a las sociedades, no sería utópico sugerir que la propia dinámica del ecosistema social acabaría con muchas de las desigualdades o injusticias que los "países avanzados" tratan de eliminar por la fuerza desde el exterior de sus fronteras, pues dichas barreras caerían desde el interior de las propias culturas que las padecen. En otras palabras, si la tecnología favorece en teoría el acceso a los recursos $y$, en consecuencia también, a la expansión cultural, el desenlace conduce inexorablemente a un crecimiento de la población y a su segmentación en formas organizativas más complejas y especializadas, relanzando así el mejor aprovechamiento de los recursos naturales y así sucesivamente, es decir dando sentido al conocido ecosistema social de un modo natural que emerge de un modo endógeno a cada sociedad y no por imposición desde las sociedades que controlan el poder a las culturas del llamado "tercer mundo".

\section{Filosofía de la Globalización}

La aceptación de la filosofía de la "globalización" está fracasando precisamente en los países avanzados, que son quienes paradójicamente, pueden extraer mayor beneficio material de las desigualdades sociales. La explicación es sencilla: Es cómodo ser solidario con las culturas desfavorecidas cuando todas las necesidades que propician un estado de bienestar están holgadamente cubiertas. Así se comprenden las diferencias entre las prioridades que preocupan a las sociedades post- materialistas y 
a las materialistas: Las primeros no pasan hambre, eligen su ropa de marca, tienen su manutención, su alojamiento, sus servicios de ocio y disfrute del tiempo libre asegurados y tampoco padecen los horrores de la ausencia de libertad de pensamiento y de libre expresión. Además, las sociedades post materialistas han alcanzado tal nivel de bienestar que ni siquiera el acceso libre a la cultura les cierra la puerta de la construcción de opiniones con cierto fundamento o conocimiento de causa. En tales circunstancias, los individuos de este primer mundo pueden manifestar con fervor su inquietud por otro tipo de cuestiones como la necesidad de preservar el medioambiente, dando lugar al demagógico "espíritu ecológico".

Por el contrario, las sociedades materialistas del tercer mundo no muestran tanta pasión por el cuidado del medio ambiente ni por las legalizaciones de colectivos gay o lesbianas, ni por la discriminación positiva a favor de las mujeres, ni por los porcentajes de representación nacional en foros internacionales ni por las demandas de mayor autonomía en sus comunidades, sin duda porque sus preocupaciones son necesariamente materialistas: Les preocupa si tendrán algo que comer el día de mañana, si tendrán alguna prenda con la que vestirse o si superarán con vida la próxima enfermedad por falta de alimentos.

Las sociedades avanzadas han permitido que, más que nunca, los países del tercer mundo conozcan con una facilidad inusual los placeres que disfruta el mundo occidental.

Nuestra forma de entender la globalización ha estado enfocada a demostrar a los regímenes dictatoriales de sociedades poco avanzadas que no existen límites de comida, vestimenta, placeres, lujo y ocio en nuestro primer mundo. Quizás hemos pretendido sublevar a los pueblos contra sus autoridades (Cuba, Irak, Irán, Venezuela...) bajo la justificación de que carecen de libertad de pensamiento y expresión y, sin embargo, el efecto ha sido opuesto al deseado. En efecto, los seres humanos que carecen de futuro o esperanza en la vida han optado con frecuencia por acudir al asalto de los países desarrollados, pero sin renegar de sus pueblos, de 
sus autoridades, de sus creencias religiosas, de sus costumbres ni de su cultura. Los habitantes de África, Sudamérica, Sudeste asiático o de la Europa del Este emigran a Norteamérica, Australia y Europa occidental buscando aquello de lo que carecen, generando flujos de población que solamente contribuyen a romper el equilibrio del ecosistema social. Es el resultado de una política mundial deliberadamente enfocada a la desigualdad, del mismo modo que la gestión de la comunicación también ha sido inequívocamente sesgada para alimentar la autocomplacencia de quienes disfrutan de las bondades del primer mundo y acallar las conciencias de quienes se auto definen como solidarios, cuando lo cierto es que la mayor parte de la población del primer mundo actúa en muchos casos por miedo al extranjero o por el placer de jugar el papel de benefactor un día al mes, eso sí, sin renunciar a su calidad de vida.

En este modo de entender la globalización, tanto los gobiernos de los países desarrollados como sus ciudadanos mantienen una actitud de complicidad, lo que explica también que los medios de comunicación elaboren conjuntamente una agenda de información estructurada sobre unos pocos minutos de información sobre los desequilibrios que afectan al ecosistema social mundial y grandes dosis de comunicación orientada al ocio y al entretenimiento, fomentando la ignorancia de la población sobre los verdaderos problemas que aquejan al mundo y potenciando los estereotipos de las sociedades desfavorecidas.

Si analizamos en profundidad la gestión de la comunicación en España, observaremos que los actores que controlan la agenda del medio actúan con la opinión pública igual que el primer mundo actúa con el tercer mundo: Procurando democratizarlo en la ignorancia cultural e informativa y otorgándole pequeños placeres que le mantengan alejado de la curiosidad por conocer su particular gestión política de la globalización.

La irresponsable gestión del poder conlleva necesariamente una inquietante gestión de la comunicación en los países desarrollados y en España en particular. Así se 
explica la disminución de nuestro espíritu critico, la disminución de nuestro instinto creativo y la disminución creciente del consumo de información en la población española. Los sucesivos estudios de opinión pública presentan un rasgo común: los altos porcentajes de "no sabe / no contesta" en cultura política, económica y general en contraposición a los profundos conocimientos manifestados en el ámbito de la cultura futbolística. Ni la información sobre los atentados del 11-M, ni las galas solidarias de recaudación de fondos, ni los informativos de televisión, ni los documentales ni la tele basura: El fútbol es el tipo de programa más visto en España año tras año. El fútbol es la primera actividad extraescolar en los colegios. Ser un futbolista famoso es la aspiración declarada por la mayoría de los niños y por sus propios padres. La retransmisión de partidos de fútbol es la principal fuente de ingresos publicitarios y la primera herramienta para obtener los mayores porcentajes de "share o cuota" tanto en televisión como en radio.

España ocupa el puesto número 25 de Europa en el número de diarios por mil lectores, por detrás de países como Turquía, Estonia o Hungría. Sin embargo, España ocupa el tercer lugar en el ranking de minutos consumidos de televisión por habitante y año, superados únicamente por Grecia e Italia, en contraposición a los países escandinavos, que presentan las cifras más elevadas de diarios por mil habitantes, al tiempo que muestran las exposiciones más bajas ante la "caja tonta".

Al valorar la gestión de la comunicación en España, bastaría con preguntarse por qué los informativos de televisión dedican unos minutos a la información política, económica y cultural, otorgando más del cincuenta por ciento del tiempo al fútbol, a otros deportes, a la información meteorológica y a las persecuciones policiales por las calles de las ciudades norteamericanas que proporcionan las agencias de noticias de Estados Unidos.

También cabría preguntarse por qué los informativos de televisión abordan cuestiones relativas al tercer mundo solamente cuando las imágenes presentan 
inundaciones, catástrofes de la naturaleza o batallas entre soldados y ciudadanos en contextos de pobreza. Semejante representación de la realidad parece algo sospechosa de sesgo. Es cierto que los países del tercer mundo están más expuestos a los conflictos bélicos, pero no es menos cierto que en muchos de ellos también existe una cotidianeidad donde los habitantes visten con normalidad, acuden a los restaurantes o a pasear, conducen vehículos como los nuestros, escuchan música pop rock tan vanguardista como la occidental, ejercen profesiones de despacho en edificios de alto standing $\mathrm{y}$, además, saben leer, saben escribir, hablan varios idiomas e incluso van vestidos. Es cierto que su nivel de vida y su calidad de vida dejan mucho que desear, pero tampoco es necesario que se nos oculte que, en dichos países, también existe un "día a día" corriente que, por supuesto, nunca nos muestran las cámaras de televisión. ¿Por qué será que todos los informativos de radio y televisión escogen y presentan las mismas noticias?; ¿es esta la gestión de la comunicación que debemos esperar en una sociedad que proclama la libertad de expresión y la libre competencia en materia de información?; ¿por qué todas las cadenas de televisión coinciden a la hora de dar paso a los bloques de publicidad?; ¿por qué todas las cadenas acostumbran a hacer coincidir la programación de sus series, de sus películas, de sus informativos y de sus anuncios?; ¿es este el resultado de una correcta gestión de la comunicación en una sociedad post materialista que presume de libre?

La globalización de la sociedad mundial y la gestión de la comunicación en la sociedad del siglo XXI padecen en realidad el mismo mal: Una aparente democratización de la información que oculta en realidad la creciente desigualdad entre quienes controlan el poder en el primer caso y quienes controlan la información en el segundo caso. Aunque bien visto, parece obvio que en ambos casos hablamos de los mismos actores.

En síntesis, para analizar el principal error de la globalización, tal como es enfocada desde "el poder", no es necesario comparar el primer mundo con el tercer mundo; es 
suficiente con analizar España, una sociedad avanzada, y comparar las infranqueables diferencias existentes entre sus individuos dependiendo de su proximidad o lejanía de los núcleos de tomas de decisión, así como su disposición o posibilidad de acceso a las fuentes de información. De ese modo se descubre que los grupos con mayor exposición a la información son los individuos de alta posición social y alto status socioeconómico familiar y ocupaciones, con edades generalmente comprendidas entre los 30 y los 49 años y residentes en zonas metropolitanas. Este grupo de españoles, el más elitista, es el que puede contrastar y desarrollar opiniones con un espíritu más crítico y fundamentado acerca del tratamiento de los temas que son convertidos en noticias por los medios de comunicación. Por el contrario, la clase mayoritaria en España, la clase media, residente en zonas urbanas y rurales, padece unos índices de exposición a la información muy bajos desde hace varios años, inferiores generalmente al nivel de equilibrio.

Este grupo ni siquiera tiene conciencia con frecuencia de su incapacidad, falta de formación o limitación cultural para contrastar o evaluar la información facilitada por los medios de comunicación con un mínimo espíritu crítico, tendiendo a aceptar las noticias conforme al tono, al sesgo y a la intención que el medio de comunicación expone. Este grupo incluye, y eso es lo más grave, a los individuos con edades comprendidas entre los 18 y los 29 años, es decir el grupo de población al que se presuponía, hace unas décadas, une espíritu más trasgresor y crítico hacia cualquier información difundida por los medios.

Tanto en las sociedades avanzadas como en las no desarrolladas, el poder siempre se ha ejercido con mayor comodidad ante una sociedad acomodada en la ignorancia. Por eso se explica que la gestión de la comunicación en la sociedad española del siglo XXI se caracterice por la apología del fútbol, de las informaciones asociadas a imágenes espectaculares (inundaciones, persecuciones), de los sucesos y la información meteorológica y la crónica rosa o amarilla, porque son los temas que menos ejercicio mental requieren $y$, a la vez, resultan entretenidos y son muy 
democráticos por cuanto todos pueden hablar de dichos temas. Sin embargo, la información de contenido cultural, político y económico es evitada y limitada a unos pocos minutos al día, porque el poder no tiene interés en que la sociedad ejercite su espíritu crítico, pues ello podría hacer peligrar su posición de dominio. Así se explica que, en pleno comienzo del siglo XXI, la herramienta tecnológica con un mayor potencial para favorecer la globalización sea empleada mayoritariamente para jugar, para acceder a contenidos de sexo, ocio y entretenimiento, mientras que las páginas especializadas en análisis en profundidad sobre las cuestiones políticas y socioeconómicas caen en el olvido.

Una investigación afirmaba que sólo el $4 \%$ de la información que aportan los clientes, los comerciales y los "call center" llega a los oídos de la alta dirección, que son los que, a priori, controlan la información. A este fenómeno lo llaman "iceberg de la ignorancia".

En otras palabras, no cesamos de escuchar y leer informaciones que nos abruman con datos explicando que el presente de la comunicación está en Internet y, para ello, se exponen estadísticas detallando los millones y millones de usuarios de todo el planeta que, cada día, acceden a la red para, supuestamente, comunicarse a través de las redes sociales, chatear, enviarse mensajes, comprar y vender productos y servicios y, por supuesto, consumir entretenimiento, ocio, información y publicidad, rompiendo las barreras del espacio y del tiempo.

Un ejemplo de ello aparece en la emergente China, el país que cuenta con la mayor cifra absoluta de internautas, un $15 \%$ de la población. Sin embargo, ¿quiénes son, dónde viven esos internautas chinos y para qué utilizan Internet?, ¿son chinos de 15 a 40 años que residen en Pekín o Shanghaï o son los cientos de millones de analfabetos e iletrados que aún padecen el modo de supervivencia de las sociedades medievales inmersos en los arrozales de la China interior, como las provincias Anhui, Jiangxi, Hunan, Guangxi o Guangdong? El Gobierno chino admite controlar y censurar miles de páginas web, entre ellas las de ONGs críticas con la situación de 
derechos humanos en China, como Amnistía Internacional, y 'Human Rights Watch', 0 las de 'webs' de tibetanos en el exilio. No es un caso aislado, las mismas censuras tienen lugar en los países desarrollados, pero adoptando formas más sutiles como la saturación y colocación abusiva de contenidos comunes en los principales portales, utilizando para ello los tan "preciados" dinamizadores de contenidos. Así se explica que, en los países desarrollados, cuando conectamos con los informativos de televisión en un país como España, la existencia de de más de 40 canales de TDT no es óbice para que la escaleta de noticias que encontramos en sus espacios informativos. Esta situación absurda se resume del siguiente modo:

Existe una realidad social que genera millones de informaciones diarias, las informaciones que conforman la "actualidad". Los medios de comunicación "eligen" aquellas informaciones de la actualidad que, en su opinión, son susceptibles de ser calificadas como "noticias o temas de interés público". Si el proceso es libre, independiente y objetivo, ¿cómo es posible que la selección de temas coincida entre cadenas de televisión, en tiempo y orden?

Son innumerables los estudios que han apuntado que los responsables de la "agenda del medio" en el mundo son cuatro:

- El poder económico,

- El poder político,

- Los holdings de comunicación, incluyendo holdings editoriales, medios y agencias de noticias,

- Los "lobbies"

Sin embargo, los acontecimientos que vivimos en 2009 y 2010 apuntan que la comunicación y la información están siendo controladas por un nuevo poder, el poder financiero, cuyas características principales son también cuatro:

- Es invisible en tamaño y difícilmente identificable, intangible. 
- No responde a una organización política, ni geográfica ni económica como los gobiernos, los países o las multinacionales.

- No se rige por códigos deontológicos ni normas orientadas al bienestar, la formación o la educación de la población.

- Su agilidad para desmantelar organizaciones, tanto si hablamos de gobiernos como de empresas o de medios de comunicación está directamente vinculada con la compra y venta de de intangibles en los mercados de valores.

- Escapan al control de la gestión de la comunicación "oficial", es decir la que se rige por códigos de conducta, normas y protocolos de actuación vinculados a una moral o a un código ético universalmente compartido.

Por eso las sociedades menos desarrolladas siguen sin tener acceso a esta información y, lo que es peor, tampoco tienen acceso a estas herramientas "globalizadoras".

Así podría explicarse la hipótesis sugerida según la cual el rechazo creciente a la globalización es la consecuencia natural de una sociedad que, desde su humilde limitación cultural, toma conciencia poco a poco de que la gestión de la comunicación está dirigida desde un poder anónimo que excede a los propios gobiernos, un poder que está orientado a aumentar las diferencias entre quienes están más próximos a dicho poder y quienes se encuentran más alejados del mismo. 


\section{Bibliografía}

DIEZ NICOLAS, Juan, (2004): El dilema de la supervivencia. Los españoles ante el Medio Ambiente. Ed. Obra Social Caja Madrid. Madrid.

VV.AA. (2004): El Libro Blanco del Simposio Internacional: "Las políticas sociales ante los retos de la nueva sociedad". Valencia. Ministerio de Trabajo y Asuntos Sociales (IMSERSO).

GHEMAWAT, Pankaj (2008): Redefiniendo la globalización: la importancia de las diferencias en un mundo globalizado. Ediciones Deusto. Barcelona

GIDDENS, Anthony (2007): Europa en la era global. Ediciones Paidós Ibérica. Barcelona.

INGLEHART, Ronald (2003): Human Values and Social Change. Findings from the Values Surveys. Brill. Leiden (Holanda).

ROBINSON, William I. (2004): A Theory of Global Capitalism: Production, Class, and State in a Transnational World. J ohns Hopkins University Press. Baltimore. 